\title{
Food Waste, Attitudes and Preferences of Young Females: A Case Study in Saudi Arabia
}

\author{
Ghada Alsawah, Wafaa Saleh *, Areej Malibari (), Maha M. A. Lashin and Tasneem AlGhamdi \\ Department of Industrial and Systems Engineering, College of Engineering, \\ Princess Nourah bint Abdulrahman University, P.O. Box 84428, Riyadh 11671, Saudi Arabia; \\ gaalsawah@pnu.edu.sa (G.A.); aamalibari@pnu.edu.sa (A.M.); mmlashin@pnu.edu.sa (M.M.A.L.); \\ TSAlghamdi@pnu.edu.sa (T.A.) \\ * Correspondence: wsshoukry@pnu.edu.sa
}

Citation: Alsawah, G.; Saleh, W.; Malibari, A.; Lashin, M.M.A.; AlGhamdi, T. Food Waste, Attitudes and Preferences of Young Females: A Case Study in Saudi Arabia. Sustainability 2022, 14, 1961. https:// doi.org/10.3390/su14041961

Academic Editor: Ada Margarida Correia Nunes Da Rocha

Received: 1 November 2021

Accepted: 19 January 2022

Published: 9 February 2022

Publisher's Note: MDPI stays neutral with regard to jurisdictional claims in published maps and institutional affiliations.

Copyright: (C) 2022 by the authors. Licensee MDPI, Basel, Switzerland. This article is an open access article distributed under the terms and conditions of the Creative Commons Attribution (CC BY) license (https:// creativecommons.org/licenses/by/ $4.0 /)$.
Abstract: Investigations of attitudes towards food waste and preferences of policies that affect sustainability has increased rapidly over the past few decades. Most research on food waste, however, has been undertaken mainly in the developed countries with very few in the developing countries. It is very important therefore to investigate food waste and attitudes towards sustainability in developing countries, especially since a huge amount of carbon emissions and other pollutants occur in the developing countries. Saudi Arabia is a rich developing country that sets its 2030 visions to tackle issues related to sustainability. Many strong policies and programs are set in place to fulfil these visions. Such attitudes towards food waste diverges between cultures as a result of differences in background, income, family structure, age, etc. The contribution of this study is that it intends to investigate attitudes and preferences on policies and programs that aim at achieving sustainability and reducing food waste for young university females in Saudi Arabia. The methodology that is adopted in this study is to design a questionnaire, arranged in 5 sections and 23 questions, to collect data from 199 students at Princess Norah Bint Abdulrahman University. The aim of the questionnaire was to evaluate attitudes and preferences of female students towards food waste in Saudi Arabia, and in particular in the city of Riyadh. A number of policies were selected for the investigation, including three categories of policies: hospitality policies, education and raising awareness, and legislation policies. The participants expressed their opinions towards policies and programs that aim at improving sustainability and reducing food waste. Each policy was assessed in terms of its level of importance and its effectiveness in achieving sustainability. Two indices were calculated to compare and assess the perception of the suggested policies: the Perceived Effectiveness Index (PEI) and the Endorsement Index (EI). The results show that while some policies are perceived as both effective and supported for implementation, some policies are perceived as most effective; however, participants were not very supportive of their implementation. Hospitality policies, such as encouraging food waste recycling and providing the option to take away leftover food, were ranked highest in terms of effectiveness to achieve the target. These findings seem to echo the Saudi society's attitudes of sustainable behaviour and positive attitudes towards food waste recycling. It should also be noted here that while the Saudi society is still a growing and developing society, it does care significantly about food waste and sustainability. The results are encouraging, and further investigations are urgently needed to better understand determinants of food waste at a household level in developing countries.

Keywords: food waste; student behaviour; effectiveness of policies; attitudes to policies on food waste; food waste in developing countries

\section{Introduction and Previous Work}

Food waste is one of the major public sectors that requires targeting to improve food safety, the world economy, food security and sustainability, and the environment. Food 
waste management is a critical element that contributes to sustainability (Yildirim et al., 2016) [1]. There is a mounting call on food-waste management and supervision as a major issue on the national and international programs and policies (Muriana 2017 [2], Sel et al., 2017 [3], Thamagason \& Pharino 2019 [4], Ellison et al., 2019 [5], Hamerman et al., 2018) [6]. Most of the research on food waste in general and in catering services have been developed in the western countries. These include Italy, Sweden, Germany and USA (Eriksson et al., 2017 [7], Oelofse \& Nahman 2013 [8], Muriana 2017 [2], Richter \& Bokelmann 2015 [9], Ellison et al., 2019 [5], Hamerman et al., 2017) [6]. Research on food waste in developing countries is relatively new. Only a few studies have been reported in developing countries, such as Turkey, Thailand and UAE (Sel et al., 2017 [3], Thamagason \& Pharino 2019 [4], Pirani and Arafat 2016) [10].

There are numerous studies that have investigated food-waste causes, impacts and solutions (Parfitt et al., (2010) [11], Jorissen et al., 2015 [12]; Williams et al., 2012 [13] and Aschemann-Witzel et al., 2015) [14]. The hospitality sector is responsible for a great amount of food waste. One of the United Nations Environment Programme (UNEP) reports claims that annually one-third of all food produced in the world is wasted or lost or not consumed. Jorissen et al., 2015 [12]; Williams et al., 2012 [13] and Aschemann-Witzel et al., 2015 [14] emphasize the need for further efforts to identify and quantify sources of food waste and ways of controlling it. Previous research suggests that culture and social customs affect not only amount of food waste but also the qualities and quantities of food waste ((UNDP). 2011-2012 [15]; Sharp et al., 2010 [16]; Evans, 2012 [17]; Koivupuro et al., 2012 [18] and Stefan et al., 2013 [19]). Therefore, further research to investigate and examine food waste and attitudes towards it as well as the policies that are planned to target these issues, are urgently needed.

There is also a body of research that has investigated how to assess the quantities of food waste, and assess and understand the attitudes towards these losses. Garcia-Herrero et al., [20] carried out a study to estimate food losses (FL) in Spain through the food supply chain (FSC). The study considered the analysis in terms of mass, economic and nutritional aspects. Their results highlight the importance of reducing FL, which accounts for almost $20 \%$ of the national food production. When economic wastage is assessed, losses at households' level constitute to almost $50 \%$ of the total economic losses. They developed a methodology that balances both nutritional and economic variables to facilitate the decision-making process for the proper food loss management

Piergiuseppe Morone et al. [21] present evidence of a possible $60 \%$ reduction in food waste for households that are associated with organic food and schemes of sharing practices. However, the study has concluded that food-sharing practices would not automatically lead to food waste reduction. Piergiuseppe Morone et al. [22], examined the emerging network structure and the collaborative links of a specific COST Action-FWV for Sustainable Chemicals, Materials and Fuels (EUBis) - which encompassed more than 140 actors including universities, large and small firms, and public and private research institutions.

Their study employed social network tools to assess the dynamic evolution of collaborative relations, focusing on knowledge exchange, joint research and project networks both before and during the EUBis Action.

The research undertaken in [23] presented representative case studies regarding the valorization of waste streams generated from various food supply chains in different regions worldwide. Extraction technologies should be combined with green chemical conversion and bioprocessing in order to take advantage of all components present in food-supply-chain waste.

The attitudes, preferences and awareness about food waste in developing countries are different to those in the western countries. Saudi Arabia is a developing country with a high income per capita. The cultural attitudes are different and are very personal. Customs and traditions in Saudi Arabia are strong, and they influence every aspect of life. Food customs are not excluded. With the growing contribution of Saudi women in many sectors as part of the Saudi national 2030 vision, greater awareness of sustainability, 
health, environmental impacts, and food waste and awareness have developed. Women in particular have a significant role to play in food waste and its management at the level of the household. Therefore, investigating attitudes and preferences of Saudi women is very crucial when it comes to investigating food-waste matters in the country. Factors relating to food-waste decisions and attitudes are very important for successful introduction of efficient communities.

There has been an increase in awareness about sustainability and environmental issues over the past few decades. Sustainability has become a major requirement and a target for all nations and many organisations. At an international level, major efforts by governments, United Nations, OECD member countries and other international organizations are undertaking great efforts to achieve sustainability in all sectors. For example, the powers put by the United Nations Framework Convention on Climate Change (UNFCCC) to achieve the goals of the Paris Agreement that aim to target climate change and strengthen the efforts that are required to attain sustainability was phenomenal. At a national level, many efforts have been put in order to identify, analyze, facilitate and target many aspects of sustainability. These include governmental bodies, industries, planners, academia and the end users. More and more concerted efforts by all parties are still needed and can make a difference. There is a chain of management and processes involved in each sector that needs to be targeted. In addition, these all must work together to optimize the outcomes. Achieving sustainability is not an easy task, however it is not impossible. Previous research has identified potential areas for raising awareness and educating a society about the environmental impacts of many sectors, including energy usage, food supply and food waste. In terms of food waste for instance, food waste needs to be identified, analyzed and assessed in order to be optimally managed and minimized. There has been considerable academic research, valuable contributions and exploration regarding food waste in hotels, restaurants, schools, factories, airlines and catering services, particularly over the last decade. The topic is gaining global and national momentum, support, funding and recognition. There are many respected advances on the subject as well as obliging opportunities that adds to its strengths. However, there are still many gaps that need further attention. For further readings on this, see the discussions in [24-28].

Effective measures to manage food waste and their impacts on public acceptability are very important. There is evidence that young women have more awareness about sustainability and environmental issues than older generations. Research in the UK (Banaji, and Buckingham, 2010) [29] indicates that, when compared to western societies, little is known about the attitudes of women towards food waste and policies related to food-waste management. In Arab countries, women's attitudes and behaviour towards food waste and its management are not only affected by economic and geographical factors, but also by other social and cultural differences and customs. Not many studies have attempted to examine women's attitudes in this area. This paper is designed to investigate attitudes and perceptions of young females in Saudi Arabia. A study investigating attitudes of female students at Princess Nourah Bint Abdulrahman University (PNU) in Riyadh in Saudi Arabia has been carried out in 2020. The paper is structured as follows. Section 1 presents the introduction and previous work. Section 2 is devoted to the methodology that is followed in this research. Section 3 presents the results and discussion. Section 4 presents conclusions of the research and suggestions for further work.

\section{Methodology}

The methodology of this research is based on the analysis and assessment of the responses of female participants at PNU in Riyadh. Four main phases are identified in this survey as presented in Figure 1 below. These are: survey preparation, survey policies, survey participants, and survey approach and analysis. 


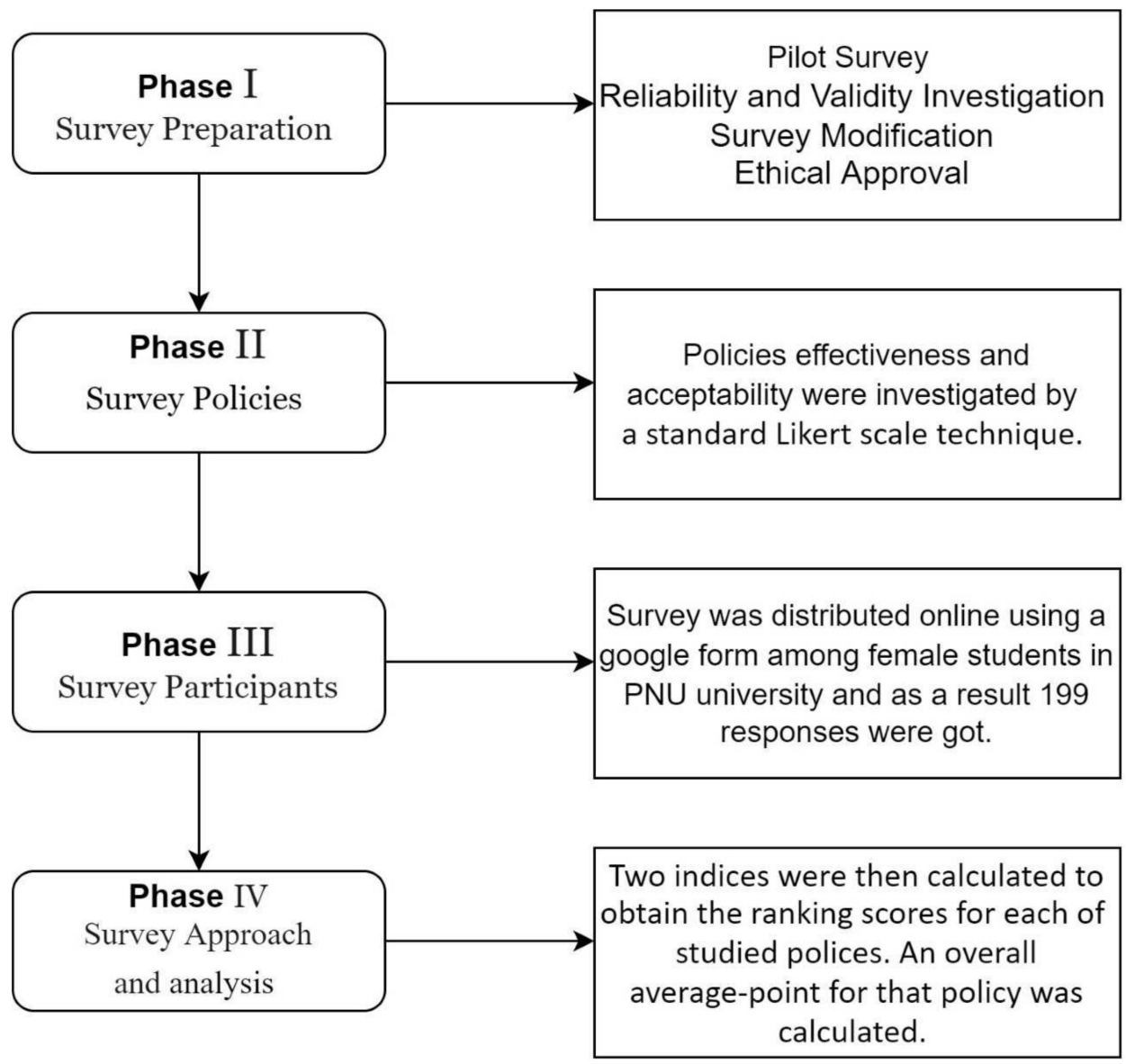

Figure 1. The four main phases that are identified in this research.

\subsection{Phase I: Survey Preparation}

A tailored questionnaire was prepared and distributed in English, as most university students and staff can manage with English. Also, the information in the questionnaire was very straight forward and not complicated. The survey is composed of an introduction to the survey and 5 sections including 23 questions. It was developed and distributed to the students at the college of engineering at PNU University in Riyadh. This research utilized an online Google form survey. In this case the questionnaires were circulated to the target population by use of an online link that was shared on WhatsApp groups or individual smart phones. The participants filled in the forms and submitted them by clicking on the submit button which updated the Excel sheet forms concurrently. A reminder message was sent to all participant a week after the initial distribution of the questionnaires in order to improve response rates. The students were also asked to distribute the questionnaire through their personal contacts. The data was collected at the Princess Nourah Bint Abdulrahman University in Riyadh in the Kingdom of Saudi Arabia. As the survey was carried out online, there was no financial compensation offered to the participants, rather their contribution was voluntarily.

Two main criteria have been utilized in order to test the reliability and validity of the survey. Firstly, the reliability of the survey was tested using the test-retest technique. To guarantee the validity of the approach used and that the responses correctly reflect the attitudes of the participants, two main comparable sets of indicators have been obtained. These are the perception of effectiveness of food waste measures and the acceptability for measures to be implemented. The two sets of indicators have been estimated using responses obtained from participants to check their validity and reliability. The outcomes are discussed in the results section. 
A pilot survey took place with 35 students to check the length of the survey and the contents. The questionnaire has been validated by carrying out the survey with a group of participants, then the survey was repeated on the same group one week later. The responses were exactly the same. This technique provided the research team with confidence in the reliability of the survey. This involves administering the survey with a group of respondents and repeating the survey with the same group at a later point in time. We then compared the responses at the two timepoints.

Various modifications have been implemented on language and structure as a result of the pilot survey The main survey is structured in four sections are as follows. The first section includes demographic characteristics of the participants, which include age, gender, income and education. Section 2 includes attitudinal questions on food waste and its impacts. Section 3 includes questions on preferences and assessment of measures and policies that target food waste management. The fourth section includes questions on areas of applications of food waste and raise awareness policies. The final section includes questions on preferences and attitudes of participants towards some policies and programs that aim at reducing food waste and enhance sustainability.

The questionnaire was distributed at PNU students using a Google form. This survey was ethically approved by the PNU Institute Review Board (IRB). The study was voluntary and no personal data were asked for to guarantee confidentiality. The objectives of the study were to assess and analyze attitudes and preference towards food waste at restaurants, and assess university students' opinions towards some policies aiming at reducing food waste.

The objective of this research is to assess and analyze female attitudes and preferences towards food waste at restaurants and assess their opinion towards some policies aiming at reducing food waste. The case study is investigated with sample of students at PNU. These attitudes were investigated by distributing a pre-designed modest questionnaire. The questionnaire is designed to investigate women's attitudes towards a number of policies aiming at managing food waste at restaurants.

\subsection{Phase II: Survey Policies}

Questionnaires are very useful research tools that can be used to collect information from the required target sample. Questionnaires should be designed to allow the respondents to express their preferences, attitudes and views, and to report on their general characteristics. In this research the questionnaire was designed to include both open-ended and closed-ended questions. A number of policies were selected for the investigation. These have been designated to be realistic and represent actual possible implementation. Three categories of measures are considered:

1. Hospitality policies

2. Education and raising awareness policies

3. Legislation policies

Table 1 below shows the three categories of policies that were investigated and were presented to the respondents.

The perception of effectiveness of these policies and the perceived level of acceptability of them to be implemented have been investigated by the female participants. A number of the closed-ended questions were designed to be centred on a Likert scale response system in order to provide optional alternative reposes. The perceived effectiveness of the policies for food waste was investigated using the Likert scale technique with a five-points rating scale. The five-point Likert scale used in the current study was represented by the following terms: significantly reduce food waste, reduce food waste, don't know, significantly increase food waste, increase food waste. The acceptability for such policies to be implemented was expressed by participants and is reported using a binary-points scale (accept or not accept). A total of 11 potential policies were tested to represent the three categories of policies. 
Table 1. The three categories of policies.

\begin{tabular}{|c|c|}
\hline Category of Policies & Selected Policies \\
\hline Hospitality policies & $\begin{array}{c}\text { P1: encourage recycling of food waste } \\
\text { P2: take away leftovers' food from restaurant } \\
\text { P3: reduce portions at restaurants } \\
\text { P4: always provide a takeaway box with the meal for } \\
\text { diners to use }\end{array}$ \\
\hline Education and raising awareness & $\begin{array}{l}\text { P5: raise awareness and educate diners } \\
\text { P6: encourage food waste donation }\end{array}$ \\
\hline Legislation policies & $\begin{array}{l}\text { P7: introduce food waste reduction targets } \\
\text { P8: encourage use of before and after dates } \\
\text { P9: reproduce as animal food } \\
\text { P10: pay taxes for leaving waste in dish } \\
\text { P11: free meals/number of leftover take away }\end{array}$ \\
\hline
\end{tabular}

\subsection{Phase III: Survey Participants}

Participants in the surveys were mainly respondents to a Google survey that was posted to university students with the aim of investigating food waste recycling. They were asked to fill in the questionnaire and in addition to forward it to any groups or network that they are members of. This method seemed to be the most economic, and yet the most efficient considering the COVID-19 constraints and restrictions. This strategy seemed to work well despite the relatively less than anticipated sample size. It is important to identify the required sample size in order to reduce cost and time of the study yet to produce statistically significant and reliable results. There were only 199 completed surveys finally received, which was not surprising as the questionnaire was online. There are numerous techniques for determining sample sizes (Lenth (2001) [30]. These include using census data when the population is small enough to survey all, using evidence from literature review based on similar studies, use the range rule of thumb that states that samples of 30 to 500 participants are adequate, use statistical tables or formulas such as Cochrans, Yamane's, sample mean etc. In this research, guidance from previous similar attitudinal studies that utilized samples in the range of 100-200 participants has been used to estimate a reasonable sample size for the study (see for example Koustanai et al., 2012 [31], Beck, and Levin (2003) [32] and Cutting et al., 2014) [33] Of 199 [30-33]. The questionnaire provided a brief of the main purpose of the study, and they were asked if they could participate in the survey. The survey was anonymous and confidential.

The questionnaire was distributed to a random sample of respondents, from which a total of 199 filled questionnaires were finally used in the analysis. It should be mentioned here that the sample was randomly selected and while it might not be representative to the population in Riyadh, it was reasonable and included all sectors of the society.

\subsection{Phase IV: Survey Approach and Analysis}

As discussed, there is an increased awareness on top of national and global efforts put forward to achieve sustainability. Major component in such efforts is to have a clear understanding of the attitudes and preferences of the population who will have a main responsibility of accepting or rejecting any polices that are implemented for this purpose. The perception of the effectiveness of food-waste policies and the acceptability of them to be implemented have been investigated by Saudi female participants. The perceived effectiveness of policies that are aiming at reducing food waste has been investigated using a standard Likert scale technique with a five-point rating scale (significantly reduce food waste, reduce food waste, don't know, significantly increase food waste and increase food waste). Table 2 below shows the form that was used to report the preferences and attitudes of the participants towards the investigated food waste polices. 
Table 2. The form that was used to report the preferences and attitudes of the participants towards food waste reduction measures.

\begin{tabular}{|c|c|c|c|c|c|c|c|}
\hline \multirow{2}{*}{$\begin{array}{c}\text { Food Waste } \\
\text { Reduction } \\
\text { Measure } \\
\text { P1, P2, .. }\end{array}$} & \multicolumn{5}{|c|}{ Perception of Effectiveness of Food Waste Measures } & \multicolumn{2}{|c|}{$\begin{array}{l}\text { Acceptability for } \\
\text { Measures to Be } \\
\text { Implemented }\end{array}$} \\
\hline & $\begin{array}{c}\text { Significantly } \\
\text { Reduce Food } \\
\text { Waste }\end{array}$ & $\begin{array}{l}\text { Reduce Food } \\
\text { Waste }\end{array}$ & Don't Know & $\begin{array}{l}\text { Significantly } \\
\text { Increase } \\
\text { Food Waste }\end{array}$ & $\begin{array}{c}\text { Increase } \\
\text { Food Waste }\end{array}$ & Accept & Not Accept \\
\hline
\end{tabular}

P1: Policy 1

P2: Policy 2

The five-point scale was represented by the values $\{5,4,3,2,1\}$. The acceptability for policies to be implemented was expressed by respondents and is reported using a two-point scale (accept or not accept). Similarly, the two-point scale were recoded as the two values $\{2,1\}$. These values were assigned to reflect the importance or strength of each policy as well as the how much is it supported for implementation. Two indices were then calculated to obtain the ranking scores for each of the 11 studied polices. The first index is labelled "effectiveness index". This index reflects the perceived effectiveness of each considered policy in terms of food waste reduction. Secondly, an index that is labelled "endorsement index". That index reflects how supportive respondents are for each of the above policy to be implemented.

The two averages (the Perceived Effectiveness Index (PEI) and Endorsement Index (EI)) of the total responses for each policy were considered to obtain the overall averagepoint for that policy. For each of the PEI and EI scores, each was calculated by adding up the sum of the assigned scores for each policy and dividing them by the total number of responses as in Equation (1) below:

$$
\text { Score }=\frac{\sum \text { Scores assigned by participants for a specific policy }}{\text { Total number of partcipants }}
$$

It should be noted that while the PEI is a score out of 5 the EI score is out of 2. It should also be noted that the higher the values of scores the higher the indication that the participants are of support to a particular policy. In other words, it indicates that more participants perceive such policies to be more effective.

It should be noted here that the two sets of indicators that have been utilized here: the perception of effectiveness of food waste measures and the acceptability for measures to be implemented, which have been used to guarantee the validity of the survey data. The two sets of indicators have shown similar patterns, as is discussed in the next section, and has been estimated using participants' responses to check their validity and reliability.

\section{Results and Discussion}

Table 3 below shows the analysis of scoring results of all the food-waste policies as expressed by the participants.

Table 3 above shows the scores of Perceived Effectiveness Index (PEI) and Endorsement Index (EI) of the food-waste polices, the Standard Deviation (SD) values and ranges in the scores related to the perceived effectiveness index (PEI). The endorsement index estimates are estimated from two values that are mostly close to 2.0. It should be noted that any PEI score value of over 4 indicates that that measure was perceived by majority of participants to be effective in improving food waste and improving sustainability. Overall, it can be seen that the legislation policies were perceived to be of less effectiveness than the hospitality policies, for example. Encourage food waste recycling (P1) was ranked highest in terms of effectiveness to achieve the target with a score of 4.658. Other polices such as P2 (take 
away leftovers food). Such findings also support previous research [34]. P9 (reproduce as animal food), P11 (free meals/number of leftover takeaway) and P6 (encourage food waste donation) were scored slightly lower than P1. They are still shown to be highly effective in achieving the target of food waste reduction with scores of $3.243,4.235,3.931$ and 3.972 , respectively.

Table 3. Arithmetic Means, Standard Deviation (SD) and Range of the Perceived Effectiveness Index (PEI) and Endorsement Index (EI) of the food-waste policies.

\begin{tabular}{ccc}
\hline $\begin{array}{c}\text { Food Waste Reduction Policies } \\
\text { P1, P2, } \ldots\end{array}$ & $\begin{array}{c}\text { Perceived Effectiveness } \\
\text { Index (PEI) (SD, Range) }\end{array}$ & $\begin{array}{c}\text { Endorsement Index } \\
\text { (EI) }\end{array}$ \\
\hline P1 & $4.658(0.25,0.97)$ & 1.854 \\
\hline P2 & $3.243(0.3,1.17)$ & 1.876 \\
\hline P3 & $2.432(0.3,1.10)$ & 1.727 \\
\hline P4 & $4.354(0.1,0.4)$ & 1.895 \\
\hline P5 & $3.426(0.2,0.7)$ & 1.267 \\
\hline P6 & $3.972(0.26,1.21)$ & 1.392 \\
\hline P7 & $3.312(0.24,0.89)$ & 1.603 \\
\hline P8 & $3.291(0.13,0.5)$ & 1.283 \\
\hline P9 & $4.235(0.21,0.8)$ & 1.869 \\
\hline P10 & $2.375(0.16,0.60)$ & 1.532 \\
\hline P11 & $3.931(0.34,1.3)$ & 1.909 \\
\hline
\end{tabular}

The level of support to the policies, indicated by Endorsement Index (EI), were also well-matching with the effectiveness of policies. Most of the values in this column are close to 2.00, which indicates a strong support for food-waste policies to be implemented. P1 attracted the highest value with a score of 1.909. Other policies such as P2 (takeaway leftover), P4 (always provide a takeaway box with the meal) and P9 (reproduce as animal food) were also indicated as highly accepted with scores of 1.876, 1.895, 1.869 respectively. These findings support the conclusions of previous research [34]. P5 (raise awareness and educate diners) seem to be attracting the least support from participants.

This level of support to policies that aim at improving the environment and reducing food waste are in line with previous research. For example, a study investigating participant perceptions, attitudes and behavioural intents toward food waste and food waste management showed very positive consumer attitudes towards environmental targets and towards reducing food waste $[35,36]$. Social characteristics were also shown to have impacts on consumers attitudes. Another study investigated the link between food waste and lifestyle in younger consumers. Household size, packaging format, price-awareness and marketing seemed to affect food waste. The study also demonstrated the impact of sociocultural factors on food waste behaviour. A study that identified the characteristics that affect the assessment of management policies and strategies for the reduction of food waste in Taiwan identified the influence of social factors as having the main impact. Other studies also indicated the relevance of social factors to the positive attitudes of participant towards environmental benefits and food waste reductions. This is in line with the findings from very limited research in the area of attitudes and perceptions of consumers towards food waste [37-39].

\section{Conclusions and Further Research}

This research presents an investigation of Saudi female students' attitudes towards food waste and policies that aim at reducing food waste. While there has been a worldwide increase in awareness about sustainability and environmental issues over the past few decades, the situation is not fully clear in most of the developing world. In particular, for 
oil rich countries where money is not an issue, it is very important to understand and develop further awareness about sustainability there. In these regions and in Saudi Arabia in particular, major contributions could well be achieved, since economic constraints are much less than they are in most developing countries, and there is a vision to new era towards 2030 and the desire to be at the international forefront. The first step to achieving sustainable behaviour, therefore, is to gain a better understanding of attitudinal behaviour and perception towards sustainability. Young females are the perfect candidates for this target. They are part of the young, educated population, and they will be responsible household behaviour in the near future, and they are hugely encouraged in the current era to take up further societal responsibilities.

The investigation includes utilizing a questionnaire that contained a number of foodwaste policies that could be implemented in Saudi Arabia in order to reduce or eliminate food waste and improve sustainability. The policies that were investigated were selected to be realistic and represent actual possible policies for implementation. A total of 11 policies categorized in three main groups were identified in the investigation: hospitality policies, education, policies to raise awareness and legislation policies. A total of 199 responses were obtained. The survey took place in November 2019 in Riyadh. The attitudes of Saudi women in Riyadh towards food waste shows strong support to hospitality and educational policies. Less support is provided to legislative policies. This is in particular an issue that warrants further attention and research and could be further investigated in future research.

Two indices were used to collect data on women's preferences and support of foodwaste polices to obtain the ranking scores for each of the 11 studied policies. The first index is labelled "effectiveness index", which reflects the perceived effectiveness of each considered policy measure. The second is index is labelled "endorsement index", which reflects how supportive respondents are for each policy measure to be implemented.

The analysis of the results of all the food waste policies as expressed by the scores of Perceived Effectiveness Index (PEI) and Endorsement Index (EI) of the food-waste polices shows that they were well supported by all participants. The legislative policies were perceived to be less effective than the enforcement policies in general. For example, P1 (encourage food waste recycling) was ranked highest in terms of effectiveness to achieve the target with a score of 4.658. This indication reflects the Saudi society's attitudes towards sustainable behaviour and positive attitudes towards food-waste recycling. Despite the high income per capita in Saudi Arabia, this healthy attitudes can lead to positive outcomes regarding sustainability. Other polices such as P2 (Take away leftovers food), P9 (Reproduce as animal food), P11 (free meals/number of leftover takeaway) and P6 (encourage food waste donation) were also perceived as highly effective in achieving the target of food waste reduction with scores of $3.243,4.235,3.931$ and 3.972 respectively. It should also be noted here that while the Saudi society is still a developing society, it does care significantly about food sustainability.

The level of support to the policies, indicated by Endorsement Index (EI), were very similar to the scores of the Effectiveness Indices (PEI). Most of the values in this category are close to 2.00, which indicates a strong support for the food waste policies to be implemented. The highest values for this category were observed for food waste policies (P1, P2, P4, P9). It is also interesting to note that the lowest policy score in this section is P5 (raise awareness and educate diners), which seemed to be attracting the least support from participants. This suggests that participants feel that they are already knowledgeable about food waste and more interested in more effective policies. Therefore, the implemented polices should be carefully selected in order to be effective and accepted by the public. While legislations are very crucial to the success of any policy, the participants in this survey did not seem to be great supporters of the legislative policies. Further research is urgently needed in the area of food waste in Saudi Arabia including comparisons between male and female opinions, comparisons with other countries and other cultures, and investigations of further policies. The research findings from this current study shows similar attitudes and behavioural 
preferences reported in previous research in the West and the far East countries. This research also revealed that there is a critical lack of attitudinal research towards food waste particularly in young age groups and in the developing countries. Further research is urgently needed.

Limitations of this study include that the sample is only limited to mostly young Saudi females, as this study presents a preliminary investigation in this recent research area. Another limitation of the study is the nature of the investigation and rather limited range of policies that can be investigated in this early-stage piece of research. The investigators of this research decided to start with this simple and straight forward list of policies in order to assess the methodology and the knowledge of the participants. Worthy practical implications from this study includes the feasibility of implementing policies and enforcement measures that are able to significantly reduce food waste in the hospitality sector. One of the more interesting implications from this research is that female members of the family could well have an important role to play in achieving food-waste reduction. Further research to investigate male attitudes to food waste and the impacts of different policies on food-waste reduction in Saudi Arabia can also help in achieving food-waste reduction goals and informing food-waste policy and enterprise.

Author Contributions: Conceptualization, W.S. and G.A.; methodology, W.S., G.A., A.M., M.M.A.L. and T.A.; software, W.S.; validation, W.S., G.A., A.M., M.M.A.L. and T.A.; formal analysis, W.S., A.M. and G.A.; resources, G.A.; data curation, G.A., M.M.A.L. and W.S.; writing-original draft preparation, W.S. and G.A.; writing-review and editing, G.A., A.M., M.M.A.L. and T.A.; project administration, G.A. funding acquisition, G.A. All authors have read and agreed to the published version of the manuscript.

Funding: This research project was funded by Princess Nourah bint Abdulrahman University Researchers Supporting Project number (PNURSP2022R 151), Princess Nourah bint Abdulrahman University, Riyadh, Saudi Arabia.

Institutional Review Board Statement: Not applicable.

Informed Consent Statement: Informed consent was obtained from all subjects involved in the study. Data Availability Statement: Not applicable.

Acknowledgments: Princess Nourah bint Abdulrahman University Researchers Supporting Project number (PNURSP2022R 151), Princess Nourah bint Abdulrahman University, Riyadh, Saudi Arabia.

Conflicts of Interest: The authors declare no conflict of interest.

\section{References}

1. Yildirim, H.; Capone, R.; Karanlik, A.; Bottalico, F.; Debs, P.; El Bilali, H. Food Wastage in Turkey: An Exploratory Survey on Household Food Waste. J. Food Nutr. Res. 2016, 4, 483-489.

2. Muriana, C. A focus on the state of the art of food waste/losses issue and suggestions for future researches. Waste Manag. 2017, 68, 557-570. [CrossRef] [PubMed]

3. Sel, Ç.; Pınarbaşi, M.; Soysal, M.; Çimen, M. A green model for the catering industry under demand uncertainty. J. Clean. Prod. 2017, 167, 459-472. [CrossRef]

4. Thamagasorn, M.; Pharino, C. An analysis of food waste from a flight catering business for sustainable food waste management: A case study of halal food production process. J. Clean. Prod. 2019, 228, 845-855. [CrossRef]

5. Ellison, B.; Savchenko, O.; Nikolaus, C.J.; Duff, B.R. Every plate counts: Evaluation of a food waste reduction campaign in a university dining hall. Resour. Conserv. Recycl. 2019, 144, 276-284. [CrossRef]

6. Hamerman, E.J.; Rudell, F.; Martins, C.M. Factors that predict taking restaurant leftovers: Strategies for reducing food waste. J. Consum. Behav. 2018, 17, 94-104. [CrossRef]

7. Eriksson, M.; Osowski, C.P.; Malefors, C.; Björkman, J.; Eriksson, E. Quantification of food waste in public catering services-A case study from a Swedish municipality. Waste Manag. 2017, 61, 415-422. [CrossRef] [PubMed]

8. Oelofse, S.; Nahman, A. Estimating the magnitude of food waste generated in South Africa. Waste Manag. Res. 2013, 31, 80-86. [CrossRef]

9. Richter, B.; Bokelmann, W. Case Study about Food Losses in German Household. In Proceedings of the 143rd Joint EAAE/AAEA Seminar, Naples, Italy, 25-27 March 2015. [CrossRef] 
10. Pirani, S.I.; Arafat, H.A. Reduction of food waste generation in the hospitality industry. J. Clean. Prod. 2016, 132, 129-145. [CrossRef]

11. Parfitt, J.; Barthel, M.; Macnaughton, S. Food waste within food supply chains: Quantification and potential for change to 2050. Philos. Trans. R. Soc. Lond. B Biol. Sci. 2010, 365, 3065-3081. [CrossRef]

12. Jörissen, J.; Priefer, C.; Braeutigam, K.-R. Food Waste Generation at Household Level: Results of a Survey among Employees of Two European Research Centers in Italy and Germany. Sustainability 2015, 7, 2695-2715. [CrossRef]

13. Williams, H.; Wikström, F.; Otterbring, T.; Löfgren, M.; Gustafsson, A. Reasons for household food waste with special attention to packaging. J. Clean. Prod. 2012, 24, 141-148. [CrossRef]

14. Aschemann-Witzel, J. Helping You to Waste Less? Consumer Acceptance of Food Marketing Offers Targeted to Food-Related Lifestyle Segments of Consumers. J. Food Prod. Mark. 2018, 24, 522-538. [CrossRef]

15. Annual Report. United Nations Development Program (UNDP). 2011-2012. Available online: https://www.undp.org/content/undp/en/home/librarypage/corporate/annual-report-2011-2012--the-sustainable-future-we-want.html (accessed on 19 April 2021).

16. Sharp, V.; Giorgi, S.; Wilson, D.C. Methods to monitor and evaluate household waste prevention. Waste Manag. Res. 2010, 28, 269-280. [CrossRef] [PubMed]

17. Evans, D. Beyond the throwaway society: Ordinary domestic practice and a Sociological Approach to Household Food Waste. Sociology 2012, 46, 41-56. [CrossRef]

18. Koivupuro, H.-K.; Hartikainen, H.; Silvennoinen, K.; Katajajuuri, J.-M.; Heikintalo, N.; Reinikainen, A.; Jalkanen, L. Influence of socio-demographical, behavioural and attitudinal factors on the amount of avoidable food waste generated in Finnish households. Int. J. Consum. Stud. 2012, 36, 183-191. [CrossRef]

19. Stefan, V.; van Herpen, E.; Tudoran, A.A.; Lähteenmäki, L. Avoiding food waste by Romanian consumers: Te importance of planning and shopping routines. Food Qual. Prefer. 2013, 28, 375-381. [CrossRef]

20. Garcia-Herrero, I.; Hoehn, D.; Margallo, M.; Laso, J.; Bala, A.; Batlle-Bayer, L.; Fullana, P.; Vazquez-Rowe, I.; Gonzalez, M.J.; Durá, M.J.; et al. On the estimation of potential food waste reduction to support sustainable production and consumption policies. Food Policy 2018, 80, 24-38. [CrossRef]

21. Morone, P.; Falcone, P.M.; Imbert, E.; Morone, A. Does food sharing lead to food waste reduction? An experimental analysis to assess challenges and opportunities of a new consumption model. J. Clean. Prod. 2018, 185, 749-760. [CrossRef]

22. Morone, P.; Falcone, P.M.; Tartiu, V.E. Food waste valorisation: Assessing the effectiveness of collaborative research networks through the lenses of a COST action. J. Clean. Prod. 2019, 238, 117868. [CrossRef]

23. Lin, C.S.K.; Koutinas, A.A.; Stamatelatou, K.; Mubofu, E.B.; Matharu, A.S.; Kopsahelis, N.; Pfaltzgraff, L.A.; Clark, J.H.; Papanikolaou, S.; Kwan, T.H.; et al. Current and future trends in food waste valorization for the production of chemicals, materials and fuels: A global perspective. Biofuels Bioprod. Biorefining 2014, 8, 686-715. [CrossRef]

24. D'Adamo, I.; Falcone, P.M.; Martin, M.; Rosa, P. A Sustainable Revolution: Let's Go Sustainable to Get Our Globe Cleaner. Sustainability 2020, 12, 4387. [CrossRef]

25. McManners, P.J. Adapt and Thrive: The Sustainable Revolution; Susta Press: London, UK, 2008; ISBN 0955736900.

26. Gallagher, V.C.; Hrivnak, M.W.; Valcea, S.; Mahoney, C.B.; LaWong, D. A comprehensive three-dimensional sustainability measure: The 'missing $\mathrm{P}^{\prime}$ of 'people' - A vital stakeholder in sustainable development. Corp. Soc. Responsib. Environ. Manag. 2018, 25, 772-787. [CrossRef]

27. Pfeffer, J. Producing sustainable competitive advantage through the effective management of people. Acad. Manag. Exec. 2005, 19, 95-106. [CrossRef]

28. Giannetti, B.F.; Agostinho, F.; Almeida, C.M.V.B.; Yang, Z.; Liu, G.; Wang, Y.; Huisingh, D. Ten years working together for a sustainable world, dedicated to the 6th IWACP: Introductory article. J. Clean. Prod. 2019, 226, 866-873. [CrossRef]

29. Banaji, S.; Buckingham, D. Young people, the internet, and civic participation: An overview of key findings from the CivicWeb project. Int. J. Learn. 2010, 2, 15-24. [CrossRef]

30. Koustanaï, A.; Van Eslande, P.; Bastien, C. Use of change blindness to measure different abilities to detect relevant changes in natural driving scenes. Transp. Res. Part F Traffic Psychol. Behav. 2012, 15, 233-242. [CrossRef]

31. Beck, M.R.; Levin, D.T. The role of representational volatility in recognizing pre- and postchange objects. Percept. Psychophys. 2003, 65, 458-468. [CrossRef]

32. Cutting, N.; Apperly, I.A.; Chappell, J.; Beck, S.R. The puzzling difficulty of tool innovation: Why can't children piece their knowledge together? J. Exp. Child Psychol. 2014, 125, 110-117. [CrossRef] [PubMed]

33. Lenth, R.V. Some Practical Guidelines for Effective Sample Size Determination. Am. Stat. 2001, 55, 187-193. [CrossRef]

34. Kim, M.J.; Hall, C.M. Can climate change awareness predict pro-environmental practices in restaurants? Comparing high and low dining expenditure. Sustainability 2019, 11, 6777. [CrossRef]

35. Mallinson, L.J.; Russell, J.M.; Barker, M.E. Attitudes and behaviour towards convenience food and food waste in the United Kingdom. Appetite 2016, 103, 17-28. [CrossRef]

36. Teng, C.-C.; Chih, C.; Yang, W.-J.; Chien, C.-H. Determinants and Prevention Strategies for Household Food Waste: An Exploratory Study in Taiwan. Foods 2021, 10, 2331. [CrossRef] [PubMed]

37. Goh, E.; Jie, F. To waste or not to waste: Exploring motivational factors of Generation Z hospitality employees towards food wastage in the hospitality industry. Int. J. Hosp. Manag. 2019, 80, 126-135. [CrossRef] 
38. Chen, H.S.; Jai, T.-M. Waste less, enjoy more: Forming a messaging campaign and reducing food waste in restaurants. Qual. Assur. Hosp. Tour. 2018, 19, 495-520. [CrossRef]

39. Sirieix, L.; Lãla, J.; Kocmanovã, K. Understanding the antecedents of consumers' attitudes towards doggy bags in restaurants: Concern about food waste, culture, norms and emotions. J. Retail. Consum. Serv. 2017, 34, 153-158. [CrossRef] 